H I S T O R I A M Í N I M A S

\title{
En la casa del deseo. Prefacio a una filosofía de la educación
}

\section{In the house of desire. Preface to a philosophy of education}

\author{
Fernando Bárcena Orbe ${ }^{*}$
}

Recibido: 18 de enero de 2021 Aceptado: 19 de enero de 2021 Publicado: 31 de enero de 2021

To cite this article: Bárcena, F. (2021). En la casa del deseo. Prefacio a una filosofía de la educación. Márgenes Revista de Educación de la Universidad de Málaga, 2 (1), 181-190

DOI: https://dx.doi.org/24310/mgnmar.v2i1.11555

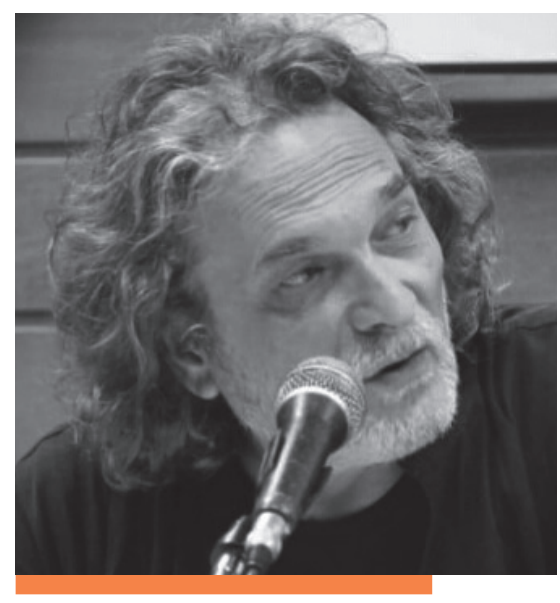

Fernando Bárcena Orbe

\section{RESUMEN}

La filosofía de la educación no es una disciplina, sino una materia instalada en una biblioteca, en una serie de lecturas y textos que, en la enseñanza, entendida como un acto de transmisión, compone un curso, para dar a leer, para dar a pensar y escribir, para permitir una conversación. Pero es, también, educación: un encuentro entre generaciones en la filiación del tiempo. La filosofía (de la educación) tiene que ver con el amor, con una especie de aumento de más hambre que no desea satisfacerse plenamente, y con el deseo, con la casa del deseo. Deseo no de conocimiento, sino de sabiduría, una que nos produce placer y dolor, una que conduce una vida y le da una forma. Este es el punto de partida aquí; mi punto de partida como profesor para pensar una filosofía de la educación. No obstante, a pesar de ese dolor que a veces nos atraviesa, o que hunde al amigo o a la amiga en el abismo, hay un último sentido en el que la educación, pensada filosóficamente — quizá como una especie de poética y como una bellísima melodía-, nos recuerda, con insistencia, la más importante ley de la educación jamás escrita por los dioses: «No te preocupes», «No pasa nada», «Yo estoy contigo», «Todo está bien». En estas expresiones se encierra la esencia de la promesa pedagógica. Prometemos lo imposible; buscamos, deseamos lo imposible, porque la esperanza nunca muere y nos conecta con la vida, pues lo posible ya es. Y lo hacemos atravesados del Eros, que es dulce y amargo, que es salud y pobreza, y aprendemos, en el amor, a habitar la casa del deseo.

Palabras clave: filosofía de la educación; deseo; poesía; teoría 


\section{ABSTRACT}

The philosophy of education is not a discipline, but a subject installed in a library, in a series of readings and texts that, in teaching, understood as an act of transmission, composes a course, to give to read, to give to think and write, to allow a conversation. But it is also education: an encounter between generations in the filiation of time. Philosophy (of education) has to do with love, with a kind of increased hunger that does not want to be fully satisfied, and with desire,h the house of desire. Desire not for knowledge, but for wisdom, one that brings us pleasure and pain, one that leads a life and gives it shape. This is the starting point here. My starting point as a teacher to think about a philosophy of education. However, despite that pain that sometimes crosses us, or that plunges the friend into the abyss, there is a last sense in which education, thought philosophically (perhaps as a kind of poetic and as a beautiful melody) he insistently reminds us of the most important law of education ever written by the gods: "Don't worry”, "Nothing happens”, "I’m with you”, "Everything is fine." These expressions contain the essence of the pedagogical promise. We promise the impossible. We look for and desire the impossible, because hope never dies and it connects us with life, because the possible already is. And we do it through Eros, which is sweet and bitter, which is health and poverty, and we learn, in love, to inhabit the house of desire.

Keywords: diversity; psychomotricity; childhood education; needs; desires

Para Mónica Garre,

"En mi paleta de color me falta azul sin ti"

(Milesa, "Huérfano")

Mi alma se marchitó y se encogió. El cuerpo se convirtió en un vestido demasiado grande para ella.

Y cuando recuperé la esperanza, era una esperanza completamente distinta.

Es dulce y amargo. Se trata de Eros. Una experiencia de placer y de dolor al mismo tiempo, dice Anne Carson en Eros dulce y amargo. Eros, que denota necesidad y carencia y deseo de lo que falta, pues desea lo que no tiene. Eros que se mantiene en el deseo y el aumento de más hambre, que si se satisface —el hambre y el deseo- se desvanece. Eros hijo bastardo de la salud y de la pobreza y que se siente en casa en la mansión del deseo. 
En última instancia, la filosofía tiene que ver con esa hambre que no desea satisfacerse plenamente, y con ese deseo, con la casa del deseo. Deseo no de conocer, no de conocimiento, sino de saber, de sabiduría, una que conduce una vida y le da forma. Este es el punto de partida; mi punto de partida para pensar una filosofía de la educación. Enseño «filosofía de la educación», que para mí no es meramente una disciplina sometida a un orden discursivo, sino una materia que enseño desde una biblioteca, desde una serie de textos que trato de leer y dar a leer a mis estudiantes. Lo que muestro en esta materia responde a una visión muy particular, que es el resultado de años de dedicación a la enseñanza de esta materia y a la lectura y estudio de los autores y autoras (filósofos o no) que más me han influido, y a los que puedo considerar también amigos. Si por algo se caracteriza la dedicación a la filosofía, aunque la apliquemos al asunto de la educación, es por la amistad, que es un principio de relación que nos mueve a estar próximos de quienes amamos. Porque amar algo, o a alguien, es querer volver a verlo una y otra vez, siempre. Lo que pasa en el amor, en toda clase de amor, es lo que en el amor nos pasa, y de eso saben los poetas, los escritores, los novelistas, los músicos y los artistas, y los filósofos y filósofas cada vez que se dejaron seducir por el arte y la belleza. Pues solo la belleza nos salva, solo la belleza.

Hago mis cursos y ordeno mis textos. Y lo primero de todo es preguntarme: ¿qué significa (dar) un curso? Para responder a esta pregunta sigo al amigo y lo que él ha dicho. Mi amigo Jorge Larrosa lo explica en algún libro reciente (por ejemplo, en $E l$ profesor artesano o en $P$ de profesor): un curso, más que un temario o una serie de contenidos (aunque los tenga) es algo que se sigue, que se recorre, como el curso de un río, y que requiere una serie de disposiciones. Un curso es un texto, o una serie de textos, que se ponen en relación con un asunto, o una serie de asuntos, textos que se dan a leer y a estudiar, para promover una conversación. Por tanto, un curso tiene que cursarse, y lo formativo en él es su recorrido, el viaje que propone a través de una serie de textos. Un curso es algo que se organiza en el tiempo, tiene un decurso temporal, como una película, una música o un libro. Seguramente, un curso no tiene conclusiones, pero sí produce efectos, que son los de cada uno, y que se darán (o no) a lo largo del curso. Un curso es una experiencia de lectura, de pensamiento, de escritura y de conversación en el que el profesor imparte una materia como lector a unos alumnos transformados en lectores y estudiantes. Ser alumno es una condición administrativa; ser estudiante es una categoría existencial. Interesa ser estudiantes y estudiosos. Como lector, el profesor da a leer, a escribir, a pensar, a conversar. Esta es su función, su oficio, en un curso. Y todo esto tiene que ver con Eros, con el amor. Hacemos nuestros cursos por amor a las lecturas y a los textos, a los libros y al mundo que mostramos a su través, por amor a los estudiantes, que acaban de llegar al aula. Es el estudiante, que sigue el curso, dirá Jorge Larrosa, quien debe recorrer por sí mismo, estudiando, los textos, quien debe realizar el viaje de su propia formación. Lo más difícil, aquí, es lograr generar las condiciones para que se active en el estudiante su deseo de saber, y para, como decía Heidegger en ¿Qué significa pensar?, dejarlo aprender. 
Cada vez más, en los últimos años, me interesa poner el acento en cierto êthos o ánimo estudioso. Pues, sin duda, lo que trato de hacer en mis cursos es estudiar (pensando, leyendo, escribiendo, conversando). Lo que en una Facultad de Educación se hace, o debería hacerse, no es otra cosa que ponerse uno a estudiar (la educación). A la escuela, y la Universidad es una forma de escuela, se va a estudiar, aunque en ella se aprendan muchas cosas, allí uno estudia junto a otros estudiantes.

Les digo a mis estudiantes que lo que vamos a hacer es estudiar filosofía de la educación, o mejor, que vamos a estudiar algunos asuntos desde una filosofía de la educación. Esa expresión «filosofía de la educación» alude a la «filosofía» y a la «educación», ambas entrelazadas. Veamos cómo.

Se dice que la palabra «filosofía» es, dicho en su literalidad, «amor a la sabiduría» (o «amor a la verdad»). En griego, la palabra «verdad» se dice así: alétheia (compuesta por dos términos: lanthánein, que significa «permanecer oculto», y léthe, que significa «olvido»). En este sentido, la «verdad» es lo que emerge de una especie de fondo oscuro y se hace presente — por tanto, inolvidable —, o, dicho de otro modo, que la verdad es eso de lo que uno no puede huir cuando uno se la encuentra. Pues bien, la filosofía surge de un pasado inmemorial, y es «teoría» (en griego theoreîn significa el que mira, el espectador o el contemplador), de modo que ejercitarse en ella requiere cierta familiaridad con toda una serie de prácticas diversas, sin que el filosofar se reduzca a ninguna de ellas: igual que la danza requiere la familiaridad con el caminar, el saltar o el escuchar, la filosofía requiere de ciertas sabidurías heterogéneas y antiquísimas, que tienen que ver con lo que los antiguos griegos llamaron «ejercicios espirituales» (atención, escucha, meditación, escritura, lectura, memoria, examen de conciencia, y otras).

Filosofía de la educación es la materia que, primero, trato de mantener vinculada con una particular forma de pensar la «filosofía», o lo «filosófico», una que hunde sus raíces en esa antigua tradición helenística que concibió la dedicación a la filosofía como el resultado de un enamoramiento personal, con una elección existencial, es decir, como una forma de vida o «ejercicio espiritual» (en el sentido griego del término) o como un «cuidado de sí» (que en griego se dice epimeleia heautou). Pero, en segundo lugar, esta materia está asociada, estrechamente unida, a una determinada manera de concebir la «educación» (a mí me gusta pensarla como un encuentro y una transmisión entre generaciones en la filiación del tiempo): la educación como un encuentro entre generaciones en la que los adultos inician a los recién llegados en el mundo (común) en el que van a vivir.

Por supuesto, la visión del mundo y de la vida de la época de la Grecia clásica era muy diferente de la nuestra hoy, pero muchas de las cosas que los filósofos griegos, y también romanos, plasmaron en sus escritos nos proporciona alguna clase de «lección» que puede ayudarnos a pensarnos hoy a nosotros mismos, en nuestro presente. Y empleo la palabra lección porque esta voz, que proviene de la palabra latina lectio, puede traducirse como lectura, es decir, como lo que se da a 
leer. Así que, si leemos, por ejemplo, las Cartas a Lucilio, de Séneca, o las Meditaciones de Marco Aurelio, o bien las Disertaciones de Epicteto o algunos diálogos de Platón, comprobaremos que para todos ellos hablar de filosofía ya consistía, sin más, en algo así como una autoeducación, una transformación o autoformación. Todos ellos insistían en la misma idea cuando se referían a la importancia del cuidado de sí: la necesidad de volver la mirada sobre uno mismo, de abandonar la agitación de allá afuera, del ruido, de la falta de silencio, dejar de curiosear en las vidas ajenas, ser más atento, evitar la indiscreción.

Dicho en unos términos quizá más actuales, a una reflexión filosófica sobre la educación le interesa la pregunta por las formas en que el individuo - en una cultura, un espacio y un tiempo dados-se constituye (o se subjetiva, por decirlo con un término muy usado por el filósofo francés Michel Foucault) como sujeto de la educación, y explorar qué es lo que entraña esta expresión (ser un «sujeto de la educación»). Por eso, un interrogante central en todo esto es: ¿Cómo se constituye el individuo en tanto que sujeto de la educación, entendida esta palabra — «educación»- desde un lenguaje de la experiencia, o sea, como el entramado que conecta campos de saber, tipos de normatividad y formas de subjetividad?

En su aplicación a la educación, la filosofía es una actividad de pensamiento que nos ayuda a formular preguntas radicales, siendo la más importante de todas la pregunta: ¿Qué clase de vida deseo vivir para que sea humana? Preguntas que tienen que ver con el sentido de la existencia, con el nacimiento y con la muerte, con el amor y con el dolor, y un largo etcétera. Preguntas que necesitamos formularnos, pero para las que no tenemos respuestas definitivas. El ser humano es un animal metafísico, como han dicho los filósofos. Y lo importante es que se haga estas preguntas; lo problemático, en cambio, que pretenda proporcionar a tales preguntas una respuesta categórica, incontestable, dogmática, definitiva. ¿Qué puedo conocer?, ¿Qué debo hacer?, ¿Qué me cabe esperar?, ¿Por qué todo lo que nace y aparece está destinado a desaparecer y morir?, en fin, ¿En qué consiste la humanidad del ser humano? ¿Algo dado por la naturaleza, o más bien una tarea, una conquista, un proyecto a realizar en el mundo? Precisamente porque nos hacemos esta clase de preguntas podemos intentar perfeccionarnos, dentro de nuestros límites, y podemos aprender, aspirando al conocimiento, buscando actuar éticamente, indagando qué podemos esperar en un mundo sin Dios o, por el contrario, creyendo que Dios existe; tratando de actuar humanamente en el orden político. De todo esto se ocupa la filosofía, que es una actividad educativa instalada en un acto de amor, de Eros. Es el tipo de preguntas que uno se hace cuando ya todo parece que está respondido y claro. Cuando uno va en busca del conocimiento, y cuando lo hace desde una actitud estudiosa y atenta, sigue siendo importante preguntarse por su utilidad humana (que no se reduce, por supuesto, a lo meramente social o económicamente «útil»). Pues bien, será «útil», en este sentido «humano», el conocimiento que permita poner en cuestión la existencia misma, o, dicho de otro modo, el saber de sí que permite producir un cambio en la propia existencia, el que, en definitiva, nos ayude a problematizar lo dado y hacer un mejor uso de 
nosotros mismos en el mundo. Podemos entender por «problematización» la actividad por medio de la cual el pensamiento se da a sí mismo un problema allí donde, anteriormente, no existía ese hábito.

Varias ideas subyacen a estos planteamientos. La primera tiene que ver con la afirmación de que el ser humano es un ser finito, un ser inscrito en el devenir del tiempo. Esto significa, entre otras cosas, que los seres humanos tenemos una idea anticipada de la muerte, lo cual, naturalmente, genera angustia, incluso desesperación, y que el ser humano es un ser que vive en un espacio y en un tiempo, en un aquíy en un ahora (en un hic et nunc). El aprendizaje filosófico tiene que ver, según esto, con el aprendizaje de nuestra finitud. Pero si la muerte es término — de eso habla un filósofo como Martin Heidegger-, el nacimiento es comienzo e inicio, como consideró la filósofa, y discípula de Heidegger, Hannah Arendt. Toda experiencia formativa supone entonces un aprender a despedirse y un aprender a comenzar algo nuevo en el mundo. La segunda idea es que el ser humano es un ser que vive, sufre y piensa, un ser de carne y hueso que tiene un cuerpo, como decían tanto Miguel de Unamuno (en Del sentimiento trágico de la vida) como Friedrich Nietzsche. Por último, el ser humano viene al mundo sin protección, no sabiendo nada de él y, por eso mismo, desorientado. Esta es la base de nuestra condición humana. Y por eso tenemos necesidad de orientación en el orden del pensamiento y de la acción, en nuestra entera relación con el mundo. Ahí se encuentra el origen de lo que denominamos «cultura». Fuera de ella, no tenemos ninguna posibilidad de supervivencia «humana» (sí, por supuesto biológica, pero no biográfica o narrativa). Por eso, el ser humano necesita aprender, formarse, educarse, y ser capaz de hacerse, como decíamos antes, las preguntas adecuadas y de pensar y comprender todo lo que ocurre mientras vive. Esto es ya, de hecho, ponerse a filosofar. Afortunadamente, llegamos a un mundo que ya estaba antes de nuestro nacimiento, y que seguirá tras nuestra partida final. Mientras estamos en el mundo establecemos relaciones con las generaciones adultas, y los que ya estaban aquí antes que nosotros nos transmiten las imágenes del mundo y nos inician y acompañan en nuestra entrada en él. En ese encuentro conversamos (con) el mundo, lo estudiamos.

En resumen, pues: el ser humano es un ser mortal y limitado en el espacio y en el tiempo: es el único ser que tiene conciencia de sus propios límites. Sabe que va a morir, y que morirán sus seres más queridos. Por eso no puede sino hacerse preguntas ante una situación que, a priori, le resulta profundamente inquietante.

Ahora bien, ¿de qué hablamos cuando nombramos la palabra «educación»? En el mundo griego, las aspiraciones culturales y educativas estaban relacionadas con la palabra griega, en cierto modo, intraducible: Paideia. Otro concepto importante es la noción alemana de Bildung, que tiene que ver con la idea que los románticos alemanes tenían de la «formación», considerada como algo no precisamente relacionado con la adquisición, diríamos en términos actuales, de habilidades o competencias. Con la palabra Bildung, en todo caso, siempre se 
trató de expresar algo que ni el término «instrucción, ni el de «socialización» o «enseñanza» lograban hacer: la autorrealización personal. En tanto que «recién llegados» al mundo, es responsabilidad de los adultos presentar a los nuevos ese mundo en el que van a vivir los jóvenes. En este sentido, la tarea educativa supone un doble amor: un amor al mundo (o Amor Mundi) y un amor a las nuevas generaciones. Dicho en los propios términos de la propia Hannah Arendt (1996):

La educación es el punto en el que decidimos si amamos el mundo lo bastante como para asumir una responsabilidad por él y así salvarlo de la ruina que, de no ser por la renovación, de no ser por la llegada de los nuevos y los jóvenes, sería inevitable. También mediante la educación decidimos si amamos a nuestros hijos lo bastante como para no arrojarlos de nuestro mundo y librarlos a sus propios recursos, ni quitarles de las manos la oportunidad de emprender algo nuevo, algo que nosotros no imaginamos, lo bastante como para prepararlos con tiempo para la tarea de renovar un mundo común. (p. 208)

Esta idea del «venir al mundo» compromete una pregunta esencialmente pedagógica en relación, no tanto con la identidad — que actualmente es abordada preferentemente como una cuestión de índole más bien sociológica y/o psicológica-, como con la subjetividad, entendida como el modo en que el ser humano, en su relación con el mundo, se transforma en sujeto de acción y responsabilidad. Venir al mundo es algo así como llegar a la presencia, «hacerse presente» en el mundo y en todo lo que hacemos y nos pasa.

Una figura destacable de la «presencia», y de esta llegada al mundo, es la «infancia», palabra que, proveniente de la palabra latina infans, significa lo que está «antes de la palabra» (de la «palabra» en el sentido del logos, del concepto organizado adultamente). La educación siempre tiene que ver con una cierta relación con la infancia (no exclusivamente con los niños), entendida la «infancia», filosóficamente hablando, como lo que comienza. De ahí que también a una filosofía de la educación le interese explorar qué significa ser un niño y que queremos decir cuando hablamos de la infancia (lo que no tiene palabras o está antes de la palabra, lo que no puede decirse, o lo inefable; literalmente: lo que no se puede hablar); la infancia no como una etapa natural de desarrollo, sino como aquello en lo que estamos cuando lo que nos pasa (un acontecimiento) nos deja «sin palabras», en una especie de estado de indigencia del lenguaje:

Los niños son nuestros dedos índices. La extensión de la realidad a partir de la atención prestada al niño se prolonga a su vez en la atención que él presta a los objetos exteriores. Los niños nos enseñan: es decir, nos enseñan, nos señalan: «Mira, una lagartija», «Mira, un avión», «Mira, una naranja». Ningún niño se queda tranquilo hasta que sus padres admiran su proeza en bicicleta, como si su existencia misma se disolviera al margen de esta mirada general constituyente [...]. Llama, reclama, les tira del manga llevado de una excitación entre metafísica y justiciera y no descansa 
hasta que los otros refrendan con su atención la existencia de lo que sólo él está viendo. Al enseñarnos apremiante la lagartija en la pared (el niño) nos enseña que la realidad es el resultado de la atención, sí, pero de una atención compartida. Entre todos ponemos las cosas en la existencia; entre todos damos un cuerpo a la estatura, un animal a la fiereza, una hoja al color verde. Gracias a los niños la humanidad, además de tener delirios íntimos, es objetiva. (Alba Rico, 2015, p. 176)

Alguien podría pensar que la actividad filosófica es, de modo exclusivo, una actividad de pensadores y eruditos solitarios alejados de los asuntos del mundo. A menudo, en la historia, fue así, desde luego. Pero el filósofo, el pensador o la pensadora, son seres del mundo. En el mundo de la antigua Grecia en realidad no existían filósofos sin un grupo de discípulos o aprendices que establecían una comunidad de afecto con sus maestros. Si la experiencia de la educación, entendida como formación, puede conectarse con lo que en la Grecia antigua se denominaba cuidado de sí, hay que recordar, entonces, como Foucault decía, que uno no puede preocuparse por sí mismo sin pasar por el encuentro con el otro; que no hay inquietud de sí sin la presencia de un maestro, de un filósofo educador.

Como pensador, el filósofo o la filósofa es un amante de la sabiduría, la verdad y de la belleza, y esa aspiración amorosa reclama de él, o de ella, una relación erótica con aquello que busca. Los filósofos y las filósofas, en fin, no dejan de establecer vínculos de amistad (que es una cierta clase de amor pedagógico) con una serie de estudiantes, discípulos y aprendices. Se trata de una relación en la que se pueden dar cita procesos de filiación, de seducción, pero también de traición. La aspiración a la filosofía pasa, según esto, por el establecimiento de un tipo de relación educativa entre maestros y discípulos, y hablar de filosofía es tener que referirse a un cierto tipo de educación, de formación o de transformación. El filósofo es ya un educador, una cierta clase de pedagogo/a; y el pedagogo/a, una cierta clase de filósofo o filósofa que busca pensar radicalmente la educación. En el hermoso ensayo del filósofo francés Georges Gusdorf ¿Para qué profesores? (2019) leemos, en este sentido, algo sumamente esclarecedor, y que evidencia la enorme responsabilidad que toda enseñanza supone:

[E]l profesor de filosofía, entre todos los profesores, tiene más oportunidades de ser un maestro. Enseña a cada uno de sus alumnos la presencia en el presente, la presencia en sí mismo. No se muestra como un pozo de sabiduría; su personaje no es el de un erudito. La clase ve en él un centro de referencia y un origen de valor; es en relación con él como cada uno está llamado a ubicarse, en el interior de un diálogo a la vez grave y cordial. El maestro de filosofía no posee la eficacia ritual del sacerdote; no se beneficia del poder sacramental ni de la puesta en escena litúrgica. Gracias a él, el espíritu se dirige al espíritu sin otro poder que el del espíritu. (p. 308)

Ahora bien, se trata de un tipo especial de «pedagogía» la que el filósofo, como educador, administra. En la antigua Grecia se daba un tipo de acompañamiento 
formativo del aspirante a la sabiduría denominado psicagogia (acompañamiento o conducción del alma), y que podemos diferenciar de la pedagogía de la siguiente manera: si es «pedagógica» la transmisión de una verdad que consiste en dotar a un sujeto cualquiera de una serie de aptitudes definidas de antemano, será «psicagógica» la transmisión de una verdad que no tiene la función de proporcionar a un sujeto un conjunto de aptitudes (o de competencias, como hoy se las denomina), sino la de modificar el modo de ser de ese sujeto al cual nos dirigimos.

Podemos intentar distinguir algunas formas contemporáneas en las que la idea de la educación —considerada como un encuentro entre generaciones en la filiación del tiempo-, se corrompe, incluso en defensa de cierta clase de discurso pedagógico. Una de tales formas es la que retrasa sine die la llegada de los individuos (niños y adolescentes) al estado de ciudadano adulto (mediante constantes procesos de infantilización que confunden la satisfacción de deseos inmediatos con las necesidades fundamentales de la formación); y otra, la que impide su entrada en la escuela (entendida esa «escuela» como un lugar suficientemente separado de la familia, el estado y el mercado), para que los sujetos aprendan mediante el estudio. Debido a esto interesa pensar qué significa ese «hacer escuela»; la escuela no como mera institución u organización, sino como un êthos, como un modo de ser y de estar, como un modo de estudiar junto a otros, como algo que tiene que ver con la preparación para acceder a un mundo común. En las admirables páginas que Albert Camus dedicó a su periodo escolar infantil, en su inacabada novela El primer hombre, encontramos un relato sobre la escuela como un espacio en el que todos los alumnos podían olvidarse de la miseria que habitaba sus hogares, un espacio donde se instauraba una especie de igualdad del comienzo (Simons y Masschelein, 2014). Al recordar sus años infantiles, el escritor Paul Auster también recuerda, en su libro Informe del interior, que sus profesores parecían haber demostrado que todo lo que él necesita aprender se encontraba en los confines de la escuela. Hablaremos pues de la forma escuela, de lo que significa entrar y habitar un aula, y de ese encuentro cara a cara entre profesores y estudiantes, un encuentro en el que se forja, sin duda, el destino de una vida.

La educación tiene que ver con la transmisión — pues los seres humanos somos herederos - pero, como decía Goethe, lo que hemos heredado de los antepasados tenemos que adquirirlo para poseerlo; y por eso, la educación tiene que ver con transmitir el mundo en sus distintas imágenes. Sin transmisión no hay duración, que es la dimensión más importante del tiempo. Algunas de estas imágenes son nobles, otras no tanto, pues están repletas de dolor, angustia, temor. Nos hacen llorar, y hacen llorar a quienes más amamos. No obstante, a pesar de todo, a pesar de ese dolor que a veces nos atraviesa y hunde al amigo, a la amiga, en el abismo, hay un sentido en el que la educación, quizá como una especie de poética, como una bellísima melodía, viene a susurrarnos, en lo más íntimo de nuestro ser, y a recordarnos, la más importante ley no escrita por los dioses de la educación: «No te preocupes», «No pasa nada», «Yo estoy contigo», «Todo está bien». En estas 


\section{H I S T O R I S M Í N I M A S}

expresiones se encierra la esencia de la promesa pedagógica. Y recordemos que un mundo sin promesas, como un mundo sin posibilidad de perdón, sería inhabitable. Prometemos (y perdonamos) lo imposible; buscamos lo imposible, porque lo posible ya es. Y lo hacemos atravesados del Eros que es dulce y amargo, que es salud y pobreza, aprendiendo a habitar la casa del deseo. Un deseo que es una esperanza que nunca muere, y que nos mantiene vivos, que sostiene la vida que busca su forma.

\section{REFERENCIAS}

Alba Rico, S. (2015). Leer con niños. Literatura Random-House.

Arendt, H. (1996). Entre el pasado y el futuro. Península.

Gusdorf, G. (2019). ¿Para qué profesores? Por una pedagogía de la pedagogía. Miño y Dávila Editores.

Larrosa, J. (2020). El profesor artesano. Materiales para conversar sobre el oficio. Laertes.

Larrosa, J. (2019). Esperando no se sabe qué. Sobre el oficio de profesor. Candaya.

Larrosa, J. y Rechia, K. (2018). P de profesor. Novedades Educativas.

Simons, M. y Masschelein, J. (2014). Defensa de la escuela. Miño \& Dávila. 